\title{
Jatropha research: A new frontier for biofuel development
}

\author{
Kinya Akashi* \\ Faculty of Agriculture, Tottori University, Tottori 680-8553, Japan \\ *E-mail: akashi.kinya@muses.tottori-u.ac.jp Tel \& Fax: +81-857-31-5352
}

With the current concerns on a challenging set of interrelated global issues, including climate change, energy crises, and depletion of natural resources, the plant biomass industry has gained increasing attention for its potential as a supplier of alternative resources for chemicals and biofuels to meet consumer demands. Jatropha (Jatropha curcas L.) is a perennial plant of the Euphorbiaceae family, and provides unique opportunities in terms of its multipurpose uses, adaptability to marginal lands in broader climates, non-competitiveness with food production, and high biomass productivity for biodiesel and other non-oil feedstock. Large-scale Jatropha cultivation projects have been initiated in the past decade in various regions in Asia, Africa, and Latin America. However, Jatropha is still essentially a wild plant and thereby requires trait improvement and the development of value-added products with the backing of sufficient science-based knowledge. These demands have stimulated recent basic research on Jatropha biology and technical development towards more efficient production and use of Jatropha biomass. The release of genome sequence information for Jatropha has further promoted various omics-based approaches towards elucidating its biological properties and advancing its technical development.
This special issue of Plant Biotechnology highlights some of the recent progress and current challenges in diverse aspects of Jatropha research and development. Ten original articles and notes represent the exciting frontier of Jatropha research. These research articles cover genome informatics, photosynthetic physiology, metabolome profiling, and genetic engineering and are aimed towards developing new sources of renewable and sustainable fuels and products. Taken together, these papers show the breadth of Jatropha science being undertaken towards profitable bioenergy production in the future.

We thank the authors of the articles featured in this issue for their contributions and thoughtful insights on key developments in the research field. We hope these papers and relevant future publications will serve as a valuable resource for advancing our technical knowledge on Jatropha production and utilization. The editing of this special issue was conducted by editors Dr. Shinjiro Ogita of Toyama Prefectural University and Dr. Taku Demura of Nara Institute of Science and Technology, and by invited editors Dr. Toshiaki Umezawa of Kyoto University and Dr. Kinya Akashi of Tottori University. We would also like to thank Ms. Nao Ohira, the manuscript manager, and invited reviewers for their help in the editorial process of this issue.

The editing of this special issue was supported by following invited editors. The chief editor deeply appreciates their assistance.

$\begin{array}{ll}\text { Kinya Akashi } & \text { Tottori University } \\ \text { Toshiaki Umezawa } & \text { Kyoto University }\end{array}$ 